\title{
Cognitive Changes in Clinical Clerkship Medical Students Who Underwent Online Enrichment in COVID-19 Pandemic
}

\author{
Ida Aju Kusuma Wardani ${ }^{1} \mathbb{D}$, Lely Kurniawan ${ }^{1} \mathbb{D}$, Christopher Ryalino ${ }^{2 *} \mathbb{D}$ \\ ${ }^{1}$ Department of Psychiatry, Faculty of Medicine, Udayana University, Bali, Indonesia; ${ }^{2}$ Department of Anesthesiology and \\ Intensive Care, Faculty of Medicine, Udayana University, Bali, Indonesia
}

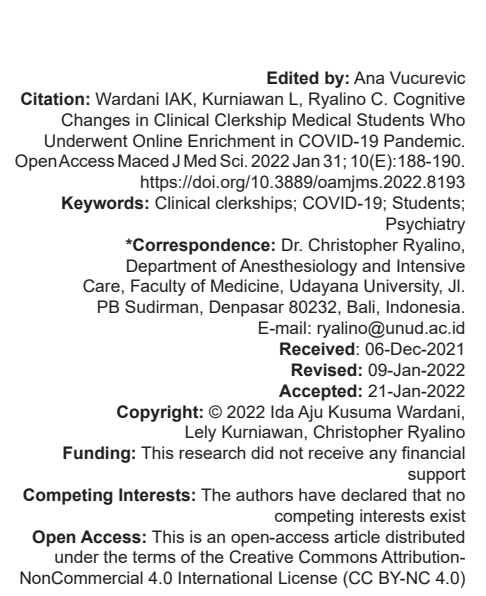

Abstract

BACKGROUND: Because of the COVID-19 pandemic, teaching methods to clinical clerkship students (CCS) at our institution was switched mainly to online method.

AIM: The purpose of this study was to determine the cognitive changes of online enrichment of CCS at the Department of Psychiatry, Faculty of Medicine, Udayana University during the COVID-19 pandemic.

MATERIALS AND METHODS: This is a descriptive and observational study. We compared two sets of students: Class of 2016 (Group N) and class of 2015 (Group F). Students in group N ( $n=99)$ experienced online enrichment in psychiatry during the $1^{\text {st }}$ week of their enrollment, while those in Group $F(n=63)$ had offline enrichment in the same topic. They answered similar pre- and post-test, and we collected and analyzed the results. We used Fisher's exact test to calculate the $p$ value.

RESULTS: The pre-test results were indifferent in both groups, 42 versus 57 in Group N and 27 versus 36 in Group F $(p=0.542)$. The post-test shows a marked improvement in terms of CCS managed to obtain the passing grade, 97 versus 2 in Group N and 55 versus 8 in Group F ( $p=0.008)$.

CONCLUSION: CCS who underwent online enrichment had a higher percentage of passing the test compared to those who underwent offline enrichment.

\section{Introduction}

The coronavirus COVID-19 was first reported in Wuhan, China, in late December 2019 and rapidly spread throughout the world [1]. This brings the world to a new era, where a so-called "a new normal" has now been implemented in every aspect of our life, including teaching [2], [3]. Online learning has several advantages, especially in this pandemic era. One known disadvantage of online learning is it highly depends on stable internet connection. The internet connection also comes with a certain price that may feel like a burden to most students [4]. Another challenge is that it requires similar coverage of internet service, which is not the case in a third-world country like Indonesia.

The switch to online learning also occurs in the Department of Psychiatry at Sanglah General Hospital, which is the main teaching hospital to medical students from Udayana University. The $1^{\text {st }}$ week's activity of clinical clerkship students (CCS), which consist of $4^{\text {th }}$ - and $5^{\text {th }}$-year medical students, is to have enrichment lectures in psychiatry. The lectures include major topics in psychiatry: Psychiatric status and interviews, psychiatric signs and symptoms, psychopharmacology, psychiatric emergencies, psychosis and mood disorders, and anxiety-andsomatoform disorders. Starting from March 2020, this enrichment lectures were carried out online. The final exam is conducted at the end of the 6-weeks enrolment. The study aims to determine if this online method has similar outcome to the previously done offline lecture method.

\section{Materials and Methods}

This is a descriptive observational, crosssectional study carried out at the Department of Psychiatry, Sanglah General Hospital, from May 2020 to September 2020. The research subjects were CCS of Udayana University enrolled in the Department of Psychiatry during the study period (Group N), which consists of three batches of students. As a comparator, we included three previous batch of CCS (Group F) 
who had their enrichment lectures carried out offline (i.e., before the pandemic). We excluded all subjects who did not attend the whole set of courses during the enrichment week.

The lecture topics, contents, and duration were similar in both groups. As this study does not involve any clinical data or intervention, the institutional ethical review board has exempted this study from the need for ethical clearance.

The evaluation instrument employed 20 multiple-choice questions on six topics covered in the enrichment, which was delivered offline for Group $F$ and by Google forms for Group N. The online test was conducted live with the onboard camera on each student's device as a supervision tool. As a baseline data, we used the pre-test conducted before the enrichment lectures. The pre-test employs similar questions to the evaluation instrument, so we can see the improvement for each student after the enrichment lectures. The minimum passing grade for the test was 70. The data were collected and processed using Microsoft Excel 2019. The results were to be presented descriptively.

\section{Results}

There were 162 subjects included in this study, 99 in Group N and 63 in Group F (Table 1). Being a $4^{\text {th }}$ year of medical school students, the most of the subjects were 22 years old. The pre-test results were indifferent in both groups, 42 versus 57 in Group $\mathrm{N}$ and 27 versus 36 in Group F ( $p=0.542)$. The post-test shows a marked improvement in terms of CCS managed to obtain the passing grade, 97 versus 2 in Group $\mathrm{N}$ and 55 versus 8 in Group F ( $p=0.008)$.

Table 1: Characteristics of the subjects and post-test results

\begin{tabular}{llll}
\hline Variables & Group N (n = 99) & Group F $(\mathrm{n}=63)$ & $\mathrm{P}$ \\
\hline Age distribution (years old), $\mathrm{n}(\%)$ & & & - \\
21 & $12(12.12)$ & $7(11.11)$ & \\
22 & $78(78.79)$ & $55(87.30)$ & \\
23 & $9(9.09)$ & $1(1.59)$ & - \\
Sex, $\mathrm{n}(\%)$ & & & \\
$\quad$ Male & $61(61.61)$ & $40(63.49)$ & \\
$\quad$ Female & $38(38.39)$ & $23(36.51)$ & \\
Pre-test results, $\mathrm{n}(\%)$ & & & \\
$\quad$ Passed $(\geq 70)$ & $42(42.42)$ & $27(42.86)$ & $0.542^{*}$ \\
$\quad$ Failed $(<70)$ & $57(57.58)$ & $36(57.14)$ & \\
Post-test results, $\mathrm{n}(\%)$ & & & $0.008^{*}$ \\
$\quad$ Passed $(\geq 70)$ & $97(97.98)$ & $55(87.3)$ & \\
$\quad$ Failed $(<70)$ & $2(2.02)$ & $8(12.7)$ & \\
${ }^{*}$ Fisher's exact test. & & & \\
& & &
\end{tabular}

\section{Discussion}

The COVID-19 pandemic has brought a switch in learning environment all over the world, including at our department that turned to online learning. The normal period of enrolment in the Department of Psychiatry was 6 weeks, but by this new era, we converted it to 5 offline weeks and 1 online week, which is our effort to reduce prolonged, unnecessary physical contact between the CCS and the patients and hospital staffs. Several aspects in medical teaching must be provided bedside, which is the reason why we kept the 5 weeks offline, to ensure that all CCS obtained necessary clinical skills and bedside experience during their enrolments.

This study showed that the CCS in Group N had a passing percentage of $97.9 \%$, compared to $87 \%$ in Group F. More CCS obtained maximum mark (the "A" mark) after online enrichment compared to offline enrichment $(80.8 \%$ vs. $1.5 \%)$. The results of this study are different from other studies, which show that the effectiveness of online enrichment is less than optimal and less effective than face-toface learning [5], [6]. The switch from offline to online teaching makes both teachers and students must adapt in terms of understanding and infrastructure. A study in the United States concluded that online courses are acceptable to students and $80 \%$ of the respondents want online learning to continue even after the pandemic is over [6]. Student performance improves compared to offline learning and students are more likely to get an A from online learning. Online enrichment made participants more confident in asking questions, increased flexibility, and increased rest time because they did not have to spend time on the road [7], [8].

Another study in Indonesia showed that during enrichment was effective but not efficient [6]. The online method is effective because of the pandemic situation that does not allow face-to-face, so it is necessary to look for other actions to optimize learning. However, it is inefficient due to several additional costs that must be incurred, such as internet bills, network problem, and less-than-optimal study environment for the students [9], [10], [11].

Online enrichment can have a positive effect on some aspects of education, but not on others, as a study of medical schools in Saudi Arabia demonstrated [10]. Face-to-face learning has the power to build interaction, discussion, and cognitive abilities [11]. Health education also requires a balance of theory and practice [11], [12], [13], [14]. Students need to have experience in dealing with patients and recognizing symptoms firsthand. This process is less effective in online learning [15]

This study has several limitations. This study was conducted in a single educational center, so generalization must be employed with caution. The online test was not supervised strictly so not to allow participants to cheat. The study was also not analyzing a causal relationship between test results after enrichment and final exam results. 


\section{Conclusion}

Young doctors $1^{\text {st }}$ week of Psychiatry KSM who underwent online enrichment had a higher percentage of passing the test compared to $3^{\text {rd }}$ week young doctors who underwent offline enrichment. Further research is needed to see the factors that play a role in the results of online and offline enrichment in young doctors of psychiatry department.

\section{References}

1. Ryalino C. Covid-19: What we know so far. Bali J Anaesthesiol. 2020;4:1-2. https://doi.org/10.4103/BJOA.BJOA_17_20

2. Dhawan S. Online learning: A panacea in the time of COVID-19 crisis. J Educ Technol Syst. 2020;49(1):5-22.

3. Ryalino C. How Indonesia copes with coronavirus disease 2019 so far (part two): Is the country ready for the new norm? Bal J Anaesthesiol. 2020;4(4):89. https://doi.org/10.4103/BJOA. BJOA_108_20

4. Akhter S, Javed MK, Shah SQ, Javaid A. Highlighting the advantages and disadvantages of E-learning. Psychol Educ. 2021;58(5):1607-14.

5. Butnaru GI, Niță V, Anichiti A, Brînză G. The effectiveness of online education during Covid 19 pandemic a comparative analysis between the perceptions of academic students and high school students from Romania. Sustainability. 2021;13(9):5311. https://doi.org/10.3390/su13095311

6. Bahasoan A, Ayuandiani W, Mukhram M, Rahmat A. Effectiveness of online learning in pandemic Covid-19. Int J Sci Technol Manag. 2020;1(2):100-6.

7. Zheng M, Bender D, Lyon, C. Online learning during COVID-19 produced equivalent or better student course performance as compared with pre-pandemic: Empirical evidence from a school-wide comparative study. BMC Med Educ. 2021;21:495. https://doi.org/10.1186/s12909-021-02909-z
8. Darling-Hammond L, Flook L, Cook-Harvey C, Barron B, Osher D. Implications for educational practice of the science of learning and development. Appl Dev Sci. 2020;24(2):97-140. DOI: 10.1080/10888691.2018.1537791

9. Yuhanna I, Alexander A, Kachik A. Advantages and disadvantages of Online Learning. JEV. 2020;1(2):13-9. https:// doi.org/10.48173/jev.v1i2.54

10. Al-Qhtani A, Al-Swedan N, Almulhim A, Aladwan R, Alessa $Y$ Al-Qhtani $\mathrm{K}$, et al. Online versus classroom teaching for medical students during COVID-19: Measuring effectiveness and satisfaction. BMC Med Educ. 2021;21(1):452. https://doi. org/10.1186/s12909-021-02888-1

11. Röhle A, Horneff $H$, Willemer MC. Practical teaching in undergraduate human and dental medical training during the COVID-19 crisis. Report on the COVID-19-related transformation of peer-based teaching in the skills lab using an inverted classroom model. GMS J Med Educ. 2021;38(1):Doc2. https://doi.org/10.3205/zma001398

PMid:33659607

12. Darras KE, Spouge RJ, de Bruin AB, Sedlic A, Hague $C$ Forster $\mathrm{BB}$. Undergraduate radiology education during the COVID-19 pandemic: A review of teaching and learning strategies. Can Assoc Radiol J. 2021;72(2):194-200. https://doi. org/10.1177/0846537120944821 PMid:32749165

13. Sharma K, Deo G, Timalsina S, Joshi A, Shrestha $N$, Neupane HC. Online learning in the face of COVID-19 pandemic: Assessment of students' satisfaction at Chitwan Medical College of Nepal. Kathmandu Univ Med J. 2020;18(70):40-7. PMid:33605237

14. Dost S, Hossain A, Shehab M, Abdelwahed A, Al-Nusair L. Perceptions of medical students towards online teaching during the COVID-19 pandemic: A national cross-sectional survey of 2721 UK medical students. BMJ Open. 2020;10(11):e042378. https://doi.org/10.1136/bmjopen-2020-042378

15. Seifert $T$, Becker $T$, Büttcher $A F$, Herwig $N$, Raupach $T$, Restructuring the clinical curriculum at University Medical Center Göttingen: Effects of distance teaching on students' satisfaction and learning outcome. GMS J Med Educ. 2021;38(1):Doc1. https://doi.org/10.3205/zma001397

PMid:33659606 